\title{
ENTREVISTA COM SÉRGIO MONTEIRO DE ALMEIDA
}

Em seu volume 10, a Revista Muitas Vozes apresenta uma conversa com o artista visual e poeta experimental Sérgio Monteiro de Almeida. Artista intermídia, Sérgio participa desde 1984, do movimento artístico do Paraná e do circuito internacional de arte postal. Como poeta visual, publicou em inúmeras antologias e revistas especializadas, tanto no Brasil como no exterior, por exemplo CULT (Brasil) e Rampike Magazine (Canadá). O artista participou de importantes exposições de poesia visual como Bienal Internacional de Poesia Visual e Alternativa no México (1987, 1990, 1992, 1996 e 2010); Post-Art International Exhibition of Visual/Experimental Poetry (San Diego State University - USA, 1988); Bienal de Veneza (2005 e 2009, curadoria de Caterina Davinio); Harvard's Visual Poetry exhibition (Harvard University, USA, 2004, 2005); Biennale Internationale de Poesie Visuelle (França, 2015, 2017, 2019, 2021). Recentemente, teve poemas publicados nos livros Davinio C. Virtual Mercury House, Planetary \& Interplanetary Events (Itália, 2012); Zúñiga A, Espinosa C. La mirada transgressora - literatura expandida (México, 2017); Dencker KP. ÜberViele/S- Begegnungen 1960-2020 (Alemanha, 2021).

\section{Revista Muitas Vozes: Considerando sua extensa produção como poeta, como você conceituaria um poema visual?}

Sérgio Monteiro de Almeida: Poesia visual é uma forma de poesia experimental que se utiliza várias formas de expressão visual como a distribuição da palavra na página de uma forma não linear, o letrismo, a caligrafia, a exploração da palavra em si como um símbolo visual muitas vezes distinto do seu significado original, com o intuito de incrementar as características semióticas e linguísticas; ou mesmo a utilização de símbolos não verbais, como uma linguagem alternativa com múltiplos significados. Outras vezes são utilizadas marcas comerciais, de comunicação de massa ou a exploração e mistura de múltiplos idiomas.

Além de explorar as múltiplas possibilidades da literatura impressa, a poesia visual também explora outras possibilidades não impressas, como poema-objetos, poesia cinética, performances, vídeos, instalações, projeções, intervenções urbanas, poesia na rede de internet (WEB), utilização de ferramentas dos aplicativos de computador como corretores de texto. O objetivo é ampliar as possibilidades de comunicação e de interpretações.

\section{RMV: Quão forte é a influência do movimento concretista brasileiro na sua produção?}

SMA: Como poeta visual do Brasil, sem dúvida, a poesia concreta brasileira dos anos 50 (Grupo Noigandres) tem influência no meu trabalho e isso é sempre evidenciado pelos 
editores de antologias e revistas em que publiquei. A produção do grupo concretista brasileiro tem grande impacto e reconhecimento na poesia experimental internacional.

Sempre fui ligado à arte e à poesia; já durante o período escolar, tive contato com os poemas de Haroldo de Campos, Décio Pignatari, Augusto de Campos e Ronaldo Azeredo. O poema “Desenho rupestre”, de Cassiano Ricardo, estava nos livros didáticos do ginásio. O poeta com o uso de uma única letra ("g”) repetida duas vezes na página, que faz referência às pinturas rupestres e também à fábula de La Fontaine “A cigarra e a formiga”. É um poema muito poderoso, que faz menção à ancestralidade dos povos originários e a cultura do colonizador europeu. A possibilidade de criar poesia independente da linearidade ou mesmo independente da palavra, como no caso do poema/ processo de Wlademir Dias-Pino, foi de grande impacto, ampliando para mim a possibilidade da poesia. Também vejo relação do meu trabalho com a poesia marginal dos anos 70, não pelo aspecto formal dos poemas, mas pela postura frente ao fazer poético, como a utilização de cópias xerox. Também tive influências de outros artistas, não necessariamente poetas, como Ligia Clarck e Hélio Oiticica, principalmente suas experiências conceituais pós-concretismo, performances e instalações.

Aqui já se faz uma diferença com a poesia concreta, pois, para o poema/processo e a poesia visual pós-concreta, o poema é uma obra aberta.

Como artista plástico, iniciei nos anos 80. Apesar da revalorização da pintura ser a característica deste período (Neo-expressionismo e Transvanguarda), sempre me interessou a arte conceitual e experimental dos anos 60-70, principalmente a intersecção de linguagens e mídias. Neste contexto, me envolvi com o circuito internacional de Arte Postal.Com isso, tive contato com a arte conceitual e poesia visual internacional de países como Itália, Alemanha e USA.

\section{RMV: A partir da sua experiência de circulação por espaços culturais, você diria que há uma diferença na receptibilidade da arte contemporânea dentro e fora do Brasil?}

SMA: Eu não diria que a questão é de receptibilidade. O que percebo fora do Brasil é que há maior número de instituições, privadas ou do governo, relacionadas com as várias formas de manifestação da arte contemporânea. Estas instituições, pelo menos a maior parte delas, publicam revistas especializadas e mantém arquivos. Além disso, as bibliotecas das universidades e museus também mantém arquivos de vários tipos de produção contemporânea e organizam exposições. Com relação à poesia, posso citar três espaços dedicados somente a poesia: a Poetry Foundation, em Chicago, a Poets House em NYC e o Center For Visual Music, em Los Angeles. As suas sedes são muito bem :localizadas e em prédios enormes, já que são instituições privadas. Elas apresentam uma atividade intensa com publicações de revistas, eventos para discussão de poetas e poesia; além disso, fornecem material do seu arquivo para exposições e para s pesquisadores. Tudo isso faz com que haja maior divulgação, registro e preservação destas formas de criação e manifestação artística, que muitas vezes são efêmeras. No Brasil, há uma produção de arte contemporânea bastante robusta, principalmente se pensarmos no pouco incentivo 
à cultura no nosso país. Porém, os espaços de exposição, arquivos em instituições públicas e publicações especializadas são escassos e muitas vezes de duração efêmera. Isso dificulta, inclusive, o conhecimento do que se produz nas diversas áreas.

\section{RMV: Tradicionalmente, considera-se a literatura como uma arte do tempo enquanto as obras visuais são colocadas genericamente no grupo das artes do espaço. Como a sua obra busca integrar as duas categorias em um mesmo texto?}

SMA: A poesia, justamente por ser uma interface entre múltiplas formas de arte e expressão, possibilita a integração entre tempo e espaço. A questão do tempo está bem presente em alguns trabalhos como "Fortuna” e "Projeto Apóstolos” (Mail ART). "Fortuna” foi uma instalação / Intervenção Urbana, exposta em vitrine da Av. Vicente Machado, Curitiba, 2012) e, posteriormente, no Museu Alfredo Andersen (Curitiba). A instalação na vitrine ocupava todo o espaço 3,5 x 4m, formada por fileiras de blocos de espuma em que foram colocadas fileiras de folha da fortuna (Kalanchoe pinnata). Os blocos de espuma eram regados diariamente ("Performance Jardineiro de Oxalá”). Em pouco tempo, começam a surgir raízes e cada folha pode gerar vários brotinhos que dão origem a uma nova planta. A folha da fortuna é considerada muito positiva e de muito prestígio, sendo usada em cerimônias iorubá. Seu nome em iorubá é àbámodá, que significa “o que você deseja, você faz”. Uma característica dessa planta é o surgimento de muitos brotos nas bordas das folhas, fato associado à prosperidade. Por isso, sua utilização é frequente nos rituais de iniciação, banhos de purificação e sacralização dos objetos rituais dos orixás. Trata-se de um trabalho de arte evolutivo e, para que aconteça, é necessária dedicação e um cuidado contínuo. A instalação tem seu tempo de evolução, definido pelo tempo da natureza e, por isso, não pode ser controlado pelo artista. O trabalho discute o ciclo da vida e também a persistência. Uma folha que gera uma nova planta em um ambiente inóspito (um bloco de espuma sintética), reafirmando o nome em iorubá da planta “àbámodá”. Não se pode prever a evolução do trabalho, pois, como se trata de uma instalação viva, as plantas podem evoluir de forma adequada ou não. A instalação evoluiu até a primeira florada e as plantas estavam com 1,5 metros de altura ( https://www.youtube. com/watch?v=erzl2pM68CA ).

No “Projeto Apóstolos” (Mail ART), a foto utilizada era a do artista ajoelhado ao lado da instalação/intervanção urbana "Pão Nosso", tirada ao lado das Ruínas da Igreja de São Francisco (Curitiba, PR, 1993 https://www.youtube.com/watch?v=pJRtaW1HgQQ ). O “Projeto Apóstolos” teve vários desenvolvimentos: (a) 1993-2017: várias cópias xerox foram distribuídas para artistas postais em todo o mundo para que interferissem na imagem. Algumas dessas intervenções podem ser vistas no site: http://enciclopedia. itaucultural.org.br/pessoa269337/sergio-monteiro-de-almeida. (b) 2007-2019: uma foto do artista quando ele tinha seis meses foi adicionada na imagem da instalação. (c) 2017 em diante: uma foto do artista com 47 anos (2012) foi colocada junto com as fotos do artista aos 28 anos (1993) e seis meses de idade (1965). Em cada fase, cópias xerox foram enviadas para artistas postais em todo o mundo. (d) "Projeto Apóstolos - Homônimos": cópia xerox distribuída por correio para homônimos dos apóstolos ou do artista, que 
moram em Curitiba, PR, Brasil. Essas pessoas foram selecionadas aleatoriamente na lista telefônica (esta ação aconteceu em 29/04/2019).

Outro exemplo em que o tempo está presente no trabalho é a instalação "Mãos ao Alto" (Sede da Fundação Cultural de Curitiba, 1997). Nesta, o poema da série "Cortes-Mãos” foi impresso em acetato e colocado nos vidros das janelas do casarão. A incidência da luz do sol projetava o poema nas paredes e no assoalho da sala de exposição, de forma que a posição das projeções se modifica de acordo com o período do dia.

\section{RMV: Qual é a importância da sensação de movimento transmitida ao leitor por poemas como “Furos" (2009) ou “Pensamento" (2009) em particular, e para a sua poesia visual como um todo?}

SMA: O poema "Furos” pertence a série “Cortes”, que surgiu quando morava em São Paulo (1992). Na série “Cortes”, eu utilizo como símbolos a linha pontilhada e a tesoura para sugerir ao espectador uma ação, que pode ou não ser realizada. Apesar de parecerem lúdicos, na verdade, são de fundo político e existencial. Os poemas desta série se referem a todos os cortes que sofremos durante a vida. A sensação de movimento nestes poemas pode estar relacionada com essa sugestão de ação e neste, mais especificamente, à repetição seriada da imagem. O poema "Furos” foi publicado no livro eletrônico Vazio (Espanha, 2009), mas é de 1993.

Com relação ao poema “Pensamento” ou “Pensamento Cerceado” (esta versão é realmente de 2009, porém é uma variação de uma versão anterior de 1994), ele também pertence à série “Cortes”. Trata-se de um fragmento de um traçado de eletroencefalograma (EEG). No início e final de cada linha do traçado há uma tesoura. Eu trabalho muito com séries e às vezes faço alterações em versões anteriores dos poemas. O EEG é um método de monitoramento eletrofisiológico que é utilizado para registrar a atividade elétrica do cérebro; por isso, pode sugerir a ideia de movimento. Esse poema foi publicado em várias antologias ao redor do mundo.

Eu tenho vários outros poemas nos quais o movimento não é apenas sugerido, mas realmente existe. A partir de 2003, quando morava em San Diego (USA), desenvolvi algumas experiências com poemas cinéticos. Posteriormente, após retorno ao Brasil, retomei esses experimentos, que fazem parte de um livro CD Eu (In) Verso, já organizado, porém inédito. Além disso, existem os vídeos de ações e intervenções urbanas.

RMV: Em sua coletânea de poemas intitulada Vazio, publicada na Espanha, em 2009, alguns de seus textos mostram a linguagem verbal se desintegrando e assumindo novas disposições pelo espaço da página. De que forma(s) essa fragmentação amplia as potencialidades do signo linguístico? Ou se trata da criação de um signo totalmente novo? 
SMA: O poema "Vazio” foi escolhido para a capa da coletânea de poemas pelos editores do livro eletrônico editado na Espanha (2009), que recebe o mesmo nome do poema (http://issuu.com/boek861/docs/sergio_monteiro_libro). Este poema foi criado após a visita a $28^{a}$ Bienal de São Paulo (2008). Nesta edição da Bienal, o $2^{\mathrm{a}}$ andar do pavilhão foi mantido totalmente vazio, em referência a crise conceitual e econômica que atravessam as instituições ligadas a arte, algo bastante atual nestes tempos pandêmicos. Creio que este poema representa bem o que você está perguntado. As letras da palavra vazio são graficamente manipuladas na página e colocadas uma em cada quadrante da página.O V e o A são a mesma letra e a letra “o” é a imagem do "Furo" da série "Cortes” colocado no centro da página, portanto com a linha pontilhada e uma a tesoura indicando a ação do corte. O "Furo" é também o ponto da letra "I".

O objetivo é alterar a imagem gráfica da palavra (imagem sensorial) para chegar a outros ou múltiplos significados. Algumas vezes transformando uma linguagem verbal em não verbal. A intenção é realmente a fragmentação da palavra, mas não com a intenção de destruição. Não entendo meu trabalho como destruição, como pode parecer para muitos. Essa postura iconoclasta tem mais a ver com o modernismo do início do século XX do que com o final do século XX e início do XXI. Coloco meu trabalho numa procura de possibilidades alternativas de comunicação, portanto, mais com uma postura pós-moderna. Neste sentido, a incorporação e associação de diversas formas de interpretação, mídias e interlinguagens procuram atingir mais amplamente o interlocutor.

A fragmentação da palavra e a associação com a linha pontilhada é uma evolução da série "Cortes", porém aqui, no lugar de corte, a linha sugere movimento ou dissociação em alguns casos. No poema “AR- - - DOR” (2020), desenvolvido durante a pandemia, o AR leva a DOR e, em alguns casos, morte; mas existe também a possibilidade de gerar Ardor que aqui pode ser febre ou paixão. Ou o poema “vA - - - Ac" publicado na revista Rampike (Dept. of English Language, Literature \& Creative Writing da Universidade de Windsor, Canadá, 2010).

RMV: Forma e conteúdo são esferas inalienáveis de qualquer produção artística. Nas suas obras, há uma complementaridade entre elas para a formação de sentido ou elas podem apontar para sentidos diferentes (ou mesmo opostos)? Em outras palavras, a significação de seus poemas está na cooperação ou na dissonância entre forma e conteúdo?

SMA: Sim, creio que as duas possibilidades. A série "Cortes", que comentei anteriormente, é um exemplo de cooperação entre forma e conteúdo; e os poemas “AR - - - DOR” ou "fe - - AR", ambos criados durante a pandemia 2020/21), podem ser exemplos de dissonância.

A partir de 2001, desenvolvi a série que chamei “Santos Contemporâneos”. Inicialmente formada por poemas impressos, a série colocava juntos propagandas de artigos de luxo com santinhos de missa, a maioria do início do século XX. O objetivo era uma justaposição de conceitos distintos, levando a novos significados. Um exemplo pode ser visto 
no site francês (http://tapin.free.fr/monteiro1.htm ; http://tapin.free.fr/monteiro2.htm). A partir desta série, criei posteriormente uma grande instalação “Degraus” na escadaria da Casa Andrade Muricy, na qual associo frases religiosas com logomarcas conhecidas e o visitante era induzido a subir ou descer pela escada, participando ativamente da instalação. ( https://www.youtube.com/watch?v=L7APDQoIGnM\&t=19s ).

Outro exemplo é a série “Ninguém disse que o amor é fácil”, que surgiu quando morava em Londres (2001). Nesta série, justaponho os cartões de propaganda das prostitutas de Londres, que coletava nas cabines telefônicas, com cartões de santos antigos, principalmente Sagrado Coração de Maria ou de Jesus. Ao mesmo tempo, fiz uma ação urbana e performance, na qual carimbava notas de R \$ 1,00 com o escrito "Ninguém disse que o amor é fácil”, estas notas eram recolocadas em circulação (https://triplov.com/sergio/ index.html). Outra série em que justaponho conceitos diferentes é a série "Lost Boys", desenvolvida quando morava em San Diego (USA, 2003), na qual justaponho imagens de propaganda de bares e clubes com a figura do Pinóquio, aqui não como símbolo de mentira como sempre é associado, mas de inocência. Na maioria destes exemplos, há dissonância entre forma e conteúdo. 


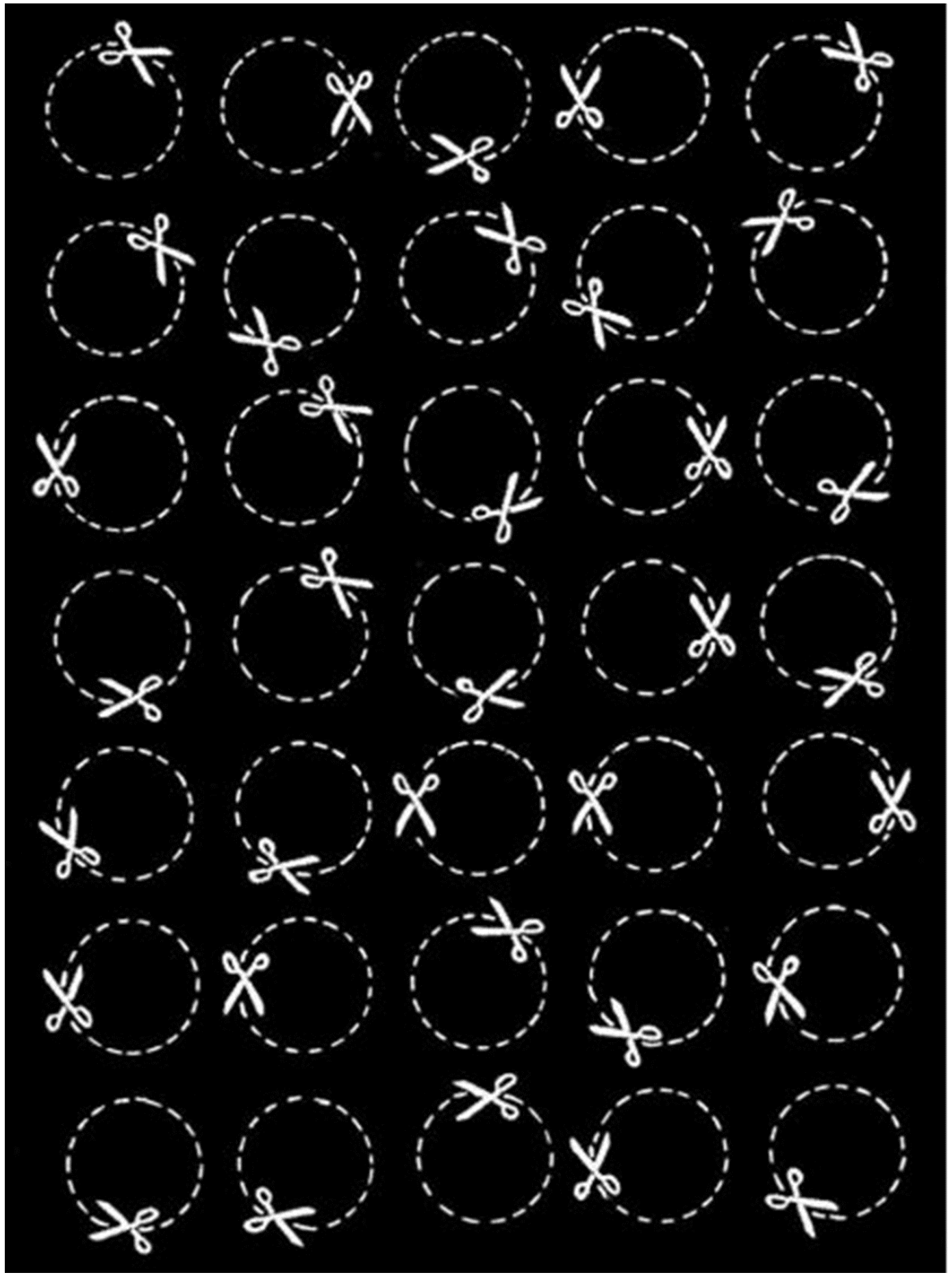



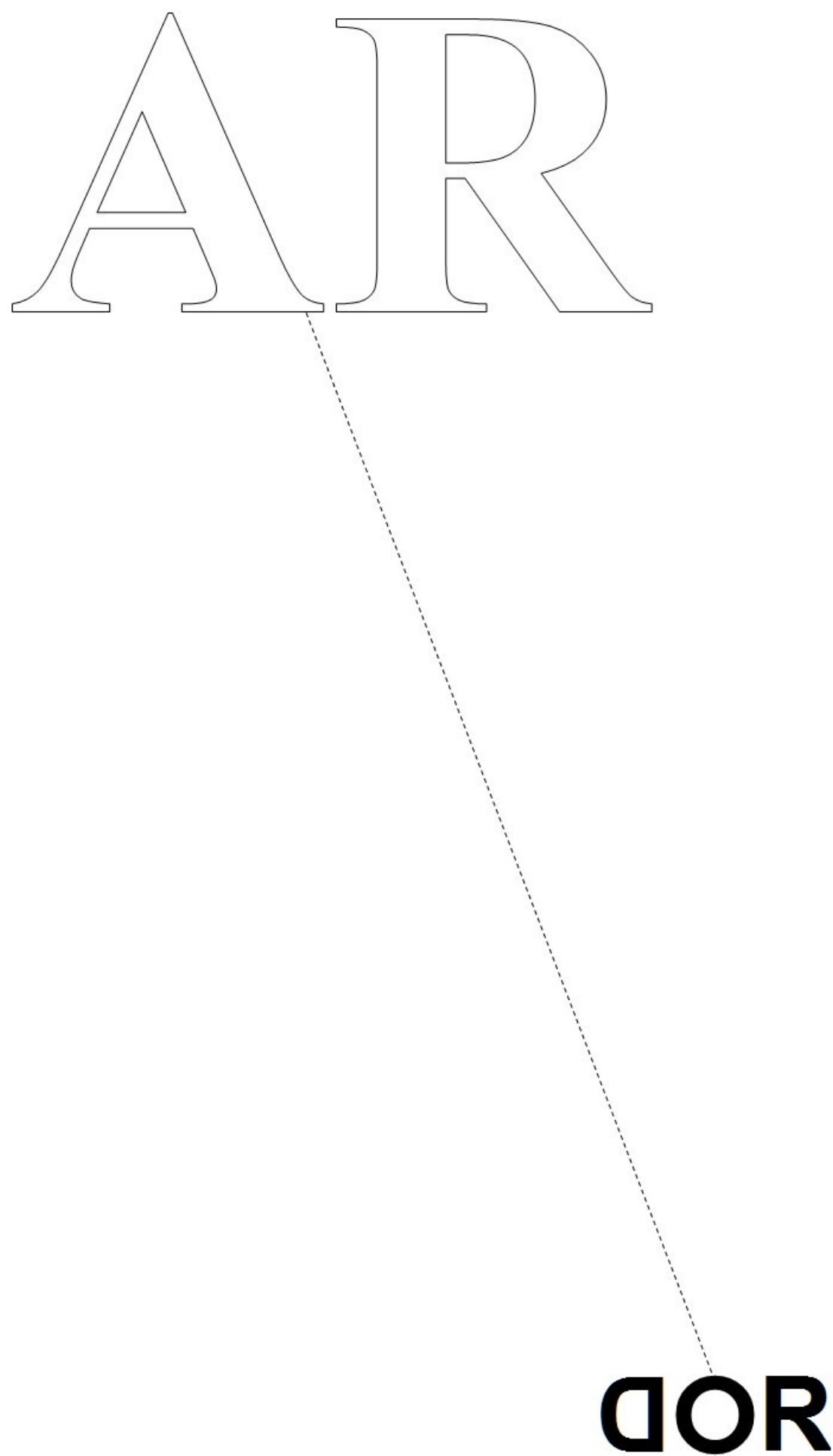

Muitas Vozes, Ponta Grossa, v. 10, p. 1-14, e-2118463, 2021.

Disponível em: http://www.revistas2.uepg.br/index.php/muitasvozes 


\section{RMV: Como se dá o seu processo de criação de um poema visual? Trata-se de uma arquitetura sempre medida e calculada ou a escrita segue seu próprio rumo?}

SMA: Na verdade, não se tratam de imagens milimetricamente pensadas e dispostas na página. Se você observar bem algumas imagens, apesar de parecerem exatas, não são. Na grande maioria dos casos, os poemas não são criados por manipulação gráfica no computador, mas sim manualmente com tesoura e cola. A presença destes erros pode ser a ligação com a poesia marginal e arte conceitual dos anos 60 e 70.

Como desenvolvo séries, uma imagem sugere outra e isso faz com que haja um fluxo de criação, como se fosse um texto sendo escrito. Apesar de alguns poemas fazerem parte de séries, os poemas funcionam de forma individual. Como alguns trabalhos exploram imagens seriadas isso os aproxima da arte minimalista, porém se afasta desta, pois não existe o rigor formal.

\section{RMV: Então, é possível que um poema analisado isoladamente e, em outro momento, no conjunto da série receba interpretações diferentes?}

SMA: Pode ser ... assim como um poema interpretado por uma pessoa pode ter uma interpretação diferente da de outra. A intenção das séries é explorar variações formais ou, em outros casos, variações conceituais, na maioria dos casos reafirmando o sentido dos poemas isolados.

\section{RMV: Qual o impacto que seus textos buscam provocar em seus leitores?}

SMA: Meu trabalho busca uma reflexão e questionamento da realidade, mesmo questionando a própria poesia. O assunto da poesia é múltiplo. Tudo que se relaciona com a natureza humana me interessa: religião, relações humanas, violência, etc. Diferentes idiomas são usados nos poemas, às vezes misturados como reflexo da nossa sociedade, uma Babel contemporânea, aonde a comunicação conduz a um esquema complexo de relacionamentos intermídia. A reunião ambígua de materiais diversos transforma e excede a mera qualidade da representação, tendo por resultado uma obra com múltiplas interpretações.

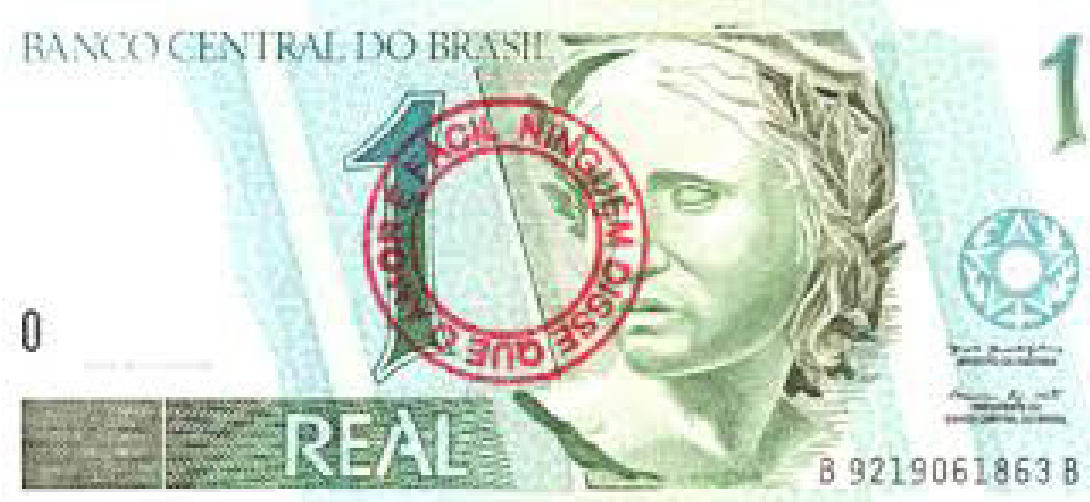


RMV: Em relação às suas ações urbanas, a interatividade característica de algumas delas pode alterar (ou alteraram) as suas expectativas em relação ao projeto inicial? Nesse caso, tanto a obra quanto o artista podem ser influenciados diretamente pelos seus leitores?

SMA: Na maioria das intervenções urbanas, não há contato direto com o expectador. A intenção é captar o transeunte com ações ou perguntas inusitadas, que, muitas vezes, mesmo subliminarmente faz o expectador pensar, como cartazes com as perguntas " $\mathrm{O}$ que você quer? / O que você realmente quer?” colocados em displays de publicidade. Essa intervenção foi realizada em várias cidades como Curitiba, Nova York, Roma, Paris (https://www.youtube.com/watch?v=xefMWBqr6wQ\&t=50s ).

Em algumas ações como “Tudo é Santo” (https://www.youtube.com/watch?v=ZlqYeOpiLJ4); "Santos Contemporâneos” (https://www.youtube.com/watch?v=WWMJt5Ho4uQ) ou "Narcissus Mirror” (https://www.youtube.com/watch?v=QFXdpWnUc2Q), há esse contato, porém, neste último a intervenção do expectador é bloqueada pela minha postura. Mminha função durante a ação é apoiar o espelho no qual o expectador terá sua imagem refletida. A comunicação é dele consigo mesmo e não comigo. Na intervenção urbana "Santos Contemporâneos”, os mesmos adesivos com frases religiosas associadas com logomarcas usados na instalação "Degraus” foram aplicados em um carrinho de uma catadora de papel, após a sua anuência. A instalação circulou pela cidade de Curitiba no carrinho da catadora. Essa catadora trabalhava com os seus filhos, um adolescente e uma menina.

RMV: Após ter participado de tantas exposições na América do Sul, nos Estados Unidos e na Europa, você acredita que seja possível identificar traços caracteristicamente brasileiros na sua poesia e na de outros artistas?

SMA: Toda criação é fruto da vivencia e experiências do artista, assim como tudo o que o cerca e o precede. Dessa forma, existem características específicas de brasilidade, porém a sua identificação, muitas vezes, não é tão clara. Em alguns períodos da nossa trajetória como, por exemplo, durante o período de governo totalitário, creio que isso era mais evidente, tanto nas criações de artistas brasileiros como de outros países da América Latina. Muitas vezes, as características de brasilidade podem ser identificadas pelo idioma português, porém, pelo menos na minha criação não é infrequente a mistura de vários idiomas. Por exemplo. o poema "Pão de Cada Dia”, iniciado na Bélgica (2003). Coletei um pacote de pão com imagens seriadas de pão baguete. Ao lado da imagem do pão, é colocada as iniciais dos dias da semana. Em cada versão do poema é usado um idioma diferente,.Inicialmente, trabalhei com idiomas que usam o alfabeto latino (português, francês, italiano, alemão e também inclui o guarani). Posteriormente, incluí outros alfabetos (japonês, chinês, hebraico, árabe, russo e grego). Costumo dizer que é o meu poema mais traduzido.

A situação social e política da América latina e do Brasil não são simples. Nossa realidade é muito diferente da realidade dos EUA ou da Europa, porém, alguns temas são universais, como, por exemplo, a violência e questões sociais. Após o atentado ao World 
Trade Center (2001), criei uma série de poemas com imagens do atentado e da guerra no Oriente Médio coletadas de jornais e carimbadas com PAX VOBIS. Uma das imagens é dos escombros do World Trade Center que parecem as ruinas de uma catedral gótica. A imagem como um todo parece uma gravura antiga (https://triplov.com/sergio/pax_vobis. html). Por ocasião da Bienal de Londres de 2004 (criada por David Medalla e Adam Nankervis), uma videoinstalação minha com um poema sobre a guerra contra o Iraque foi projetado em uma igreja de Londres. O poema dizia: “O que Deus faz enquanto o homem faz guerra, escrito sobre fundo vermelho”. Não creio que seja fácil identificar brasilidade nos poemas, mesmo nos poemas da série “Cortes”, mas também não é claro para mim se há essa necessidade.

\section{RMV: Dado o ritmo frenético da vida contemporânea, você vislumbra um espaço para a poesia no cotidiano das pessoas? Ou o cotidiano deve ser o espaço a ser po- etizado e vislumbrado?}

SMA: Fazer poesia ou arte é uma forma de interpretar e se relacionar com o mundo, independente do ritmo ou estilo de vida. Não é uma fuga da realidade, muito pelo contrário. A visão romântica do poeta que divaga idilicamente em busca da inspiração não existe e nunca existiu. A inspiração está relacionada com o cotidiano, como, por exemplo, um fragmento de texto coletado na rua ou colado nos postes públicos, propagandas diversas ou acontecimentos É uma forma de ver o mundo. Muitas vezes, o que de melhor acontece em termos de arte contemporânea está no espaço público e não em instituições.

\section{RMV: Quais são seus próximos rumos e projetos nas artes visuais?}

SMA: Durante a pandemia, estou desenvolvendo alguns poemas visuais e projetos de arte na WEB, tendo o medo como tema. O medo é o principal sentimento que caracteriza essa época. O medo é uma emoção básica, mecanismo de defesa animal adaptável, fundamental para a sobrevivência e envolve vários processos biológicos de preparação para uma resposta a possíveis eventos ameaçadores. O surgimento da pandemia pelo SARS-CoV-2 colocou o mundo inteiro frente a um futuro incerto. Esta é uma situação inédita na história recente da humanidade e tem sido comparada aos grandes desastres e catástrofes vividas pela humanidade. A pandemia expõe a fragilidade do ser humano e de todo o sistema econômico, social e cultural desenvolvidos pela humanidade e das crenças neles depositadas. Tudo isso causado por um agente etiológico invisível, até há pouco tempo desconhecido. Representa um grande desafio para a sociedade porque testa sua capacidade de lidar com uma ameaça multifacetada sob as limitações da situação.

O título é Você tem Medo? Os objetivos deste trabalho são explorar a comunicação interpessoal através da WEB com um sistema de documentos em hipermídia que são interligados e executados na Internet; e a interligação entre arte e ciência. O projeto enfoca um tema comum a todos: a pandemia de SARS-CoV-2 (COVID-19) e um sentimento global, o medo. Este projeto abarca várias formas de expressão como a ação pela internet, 
cartaz e literatura expandida (poesia visual), fazendo a interface com diversas áreas do conhecimento como arte, ciência, neurociências e sociologia. O projeto engloba um questionário eletrônico de circulação online: https://cutt.ly/CyjD9kX ; cartaz/ poema visual com QR code e a pergunta: Você tem medo? O QR code direciona para o questionário online. Esse cartaz foi colocado em pontos de circulação da cidade (intervenção urbana).

Qual a cor do medo? Projeto de poesia conceitual na WEB, link do questionário: https:// forms.gle/ZRpiCgKDUwWEHrWQ7

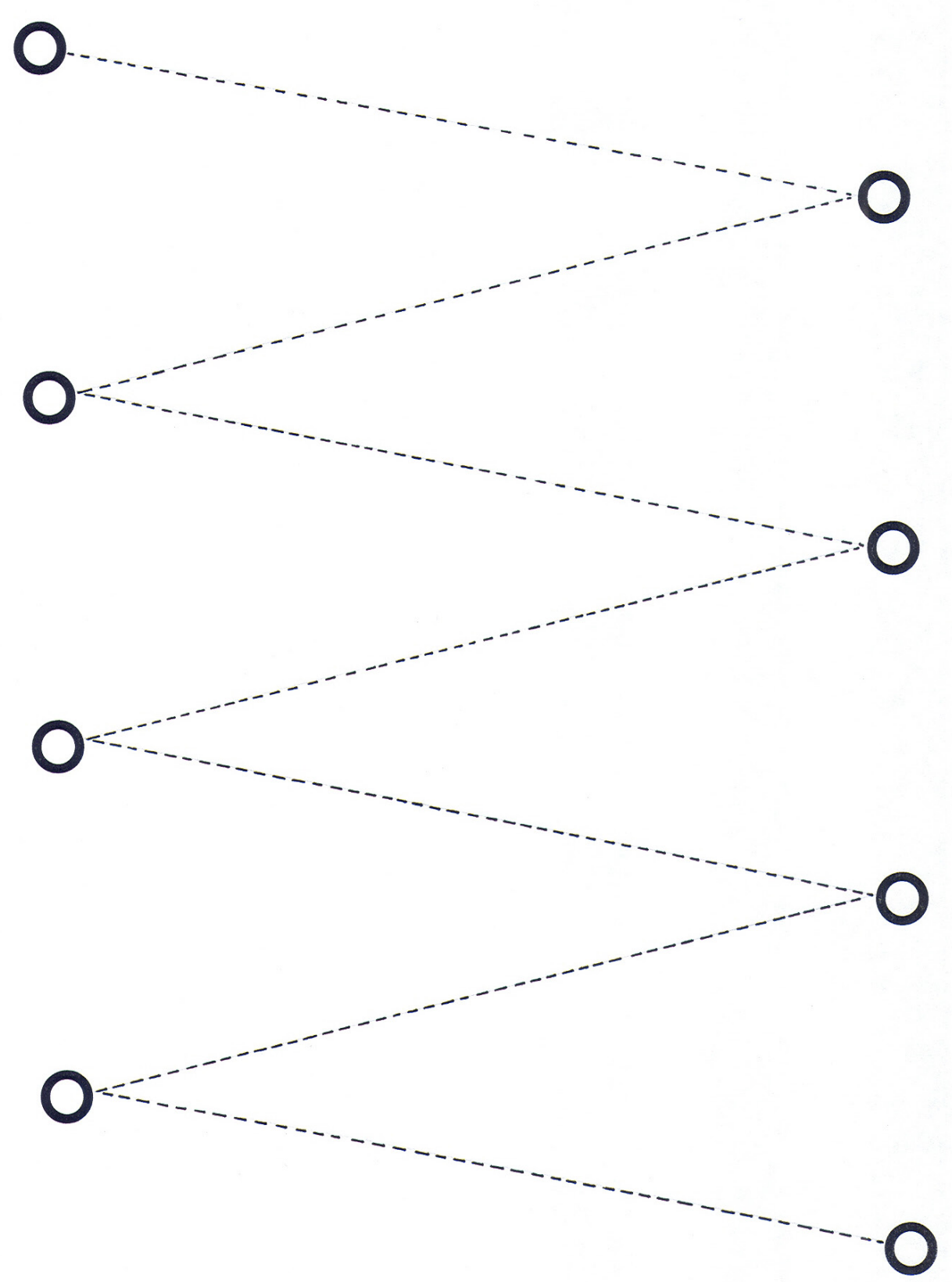


RMV: Nos cursos de Letras, cotidianamente encontramos alunas e alunos que almejam trilhar o caminho da criação artística. Se você pudesse lhes dar alguma orientação para as suas trajetórias, para onde você apontaria?

SMA: È difícil dar alguma orientação ... Não acredito nisso, simplesmente porque quem cria não sabe por que cria. Ainda mais no nosso país... O ser humano é um ser produtivo e a arte faz parte deste universo criativo. É a forma que algumas pessoas têm de perceber o universo e se comunicar com ele. A curiosidade e a informação são importantes.

Em alguns paises, como os EUA, todos os artistas ou escritores, criadores em geral, saíram de universidades. Seria quase impossível atualmente se inserir no mercado de arte sem ter cursado curso superior na area de atuação. Uma das explicações seria os contatos realizados no ambiente acadêmico, tanto com os colegas quanto com professores. Aqui no Brasil é diferente. Porém, independentemente de qualquer estímulo ou conhecimento, algumas pessoas vão criar, mesmo provenientes de situações as mais inóspitas possíveis. Só para citar três exemplos o artista visual Arthur Bispo do Rosário, a escritora Carolina Maria de Jesus, sem falar no poeta simbolista Cruz e Souza. São pessoas que teriam tudo para não fazer arte, e ainda assim possuem uma obra surpreendente.

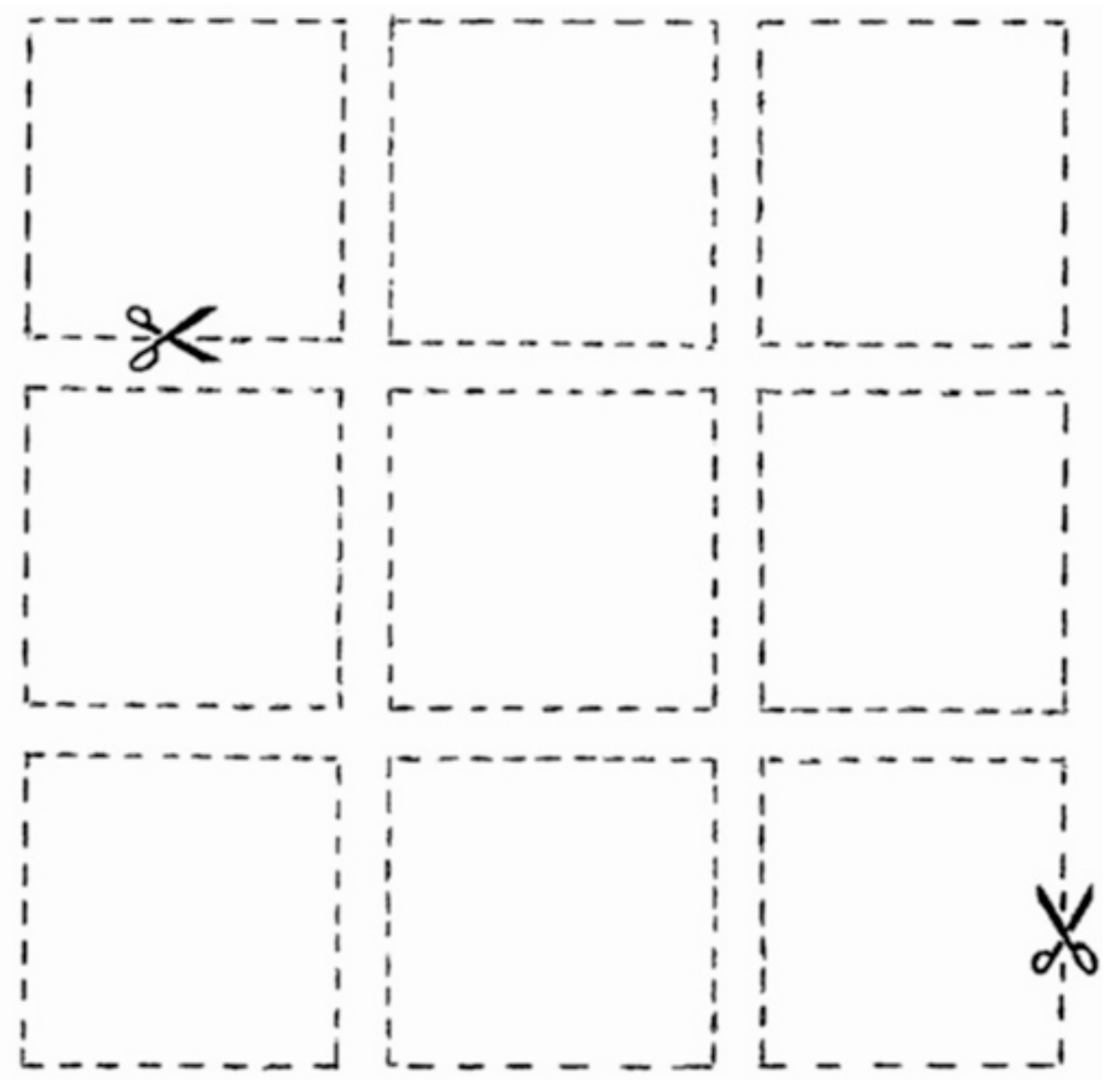




\section{Índice de obras apresentadas nesta entrevista:}

1. Série Cortes: Furos;

2. Ar _- DOR;

3. Ninguém disse que o amor é fácil Ação urbana, intervenção em notas de um real;

4. O;

5. Série Cortes: quadrados.

Onde encontrar mais sobre o trabalho do artista:

http://www.youtube.com/user/SergioMAlmeida

Livro eletrônico http://issuu.com/boek861/docs/sergio_monteiro_libro

Enciclopédia Itaú Cultural de artes visuais

http://enciclopedia.itaucultural.org.br/pessoa269337/sergio-monteiro-de-almeida 